\title{
Is part of ageism actually ableism?
}

\author{
Mariska van der Horst $^{1 \star}$ (D) and Sarah Vickerstaff ${ }^{2}$ \\ ${ }^{1}$ Department of Sociology, Vrije Universiteit Amsterdam, Amsterdam, The Netherlands and ${ }^{2}$ School of \\ Social Policy, Sociology and Social Research, University of Kent, Canterbury, UK \\ *Corresponding author. Email: m.f.j.vanderhorst@vu.nl
}

(Accepted 8 December 2020; first published online 7 January 2021)

\begin{abstract}
Ageism is a widely used term that is not (yet) well understood. We propose a redefinition of ageism and to separate it from ableism. We believe this to be important as remedies may depend on whether someone is experiencing ageism or ableism. While focusing the discussion on older workers as a sub-group of older people who (can) experience ageism, we assess the usefulness of critical (feminist) disability studies for ageism research. We hope that redefining ageism and analytically separating it from ableism (without suggesting that both concepts should be studied independently from one another) will provide guidance for researchers who study ageism and will allow for more specific policy guidance on how to solve difficulties experienced by older workers.
\end{abstract}

Keywords: ageism; ableism; disability; extended working lives

\section{Introduction}

There is increasing interest in the concept of ageism. A Google Scholar search for 'ageism' gave about 1,180 results for the year 2000, 2,800 for 2010 and 5,180 for 2019 (search conducted 17 March 2020). However, the concept is not well understood. For example, a recent study showed that the various ways that researchers measure ageism do not seem to capture one common construct (Lee et al., 2019). Higgs and Gilleard (2020: 1618) recently challenged the current use of the concept of 'ageism' as it has become a catch-all concept. In this contribution, we agree with Higgs and Gilleard that we need to be careful what we call 'ageism', but identify a different problem with the concept, namely that it ignores ableism. We do this by answering the question: is part of ageism actually ableism? The focus here is on older workers as a sub-group that experiences ageism, leading to the question: if there were no ableism, how much ageism would older workers still experience? By proposing a new definition of ageism, we aim to contribute to the clarity and usefulness of the concept.

In order to make our argument, we start by defining disability and ableism, mainly using the social relational approach of Thomas (1999). We then move on 
with definitions and current critique on ageism, before applying Thomas' social relational approach to the concept of ageism. Third, we discuss previous research that assessed overlap or intersections between ageism and ableism, and situate our approach in this literature. Fourth, we narrow the discussion to older workers and exemplify our approach using this topic. Fifth, we consider the hypothetical situation where, if we got rid of ableism, to what degree would there still be ageism? We identify multiple theoretical perspectives that suggest at least some ageism would remain. Finally, in the concluding remarks, we summarise our suggestion as well as why this matters.

\section{Defining disability and ableism}

To be able to distinguish ageism from ableism, we begin by defining disability. An important place to start is to distinguish the individual/medical model from the social model of disability. Much of this discussion underpins how we believe we should think about ageism, as will be explained later. The individual/medical model attributes all problems that individuals experience to their impairment: disability is seen as a personal tragedy (Oliver, 2009). This model has been related to the medicalisation of disability; disabled people 'have something wrong with them' and 'need to be fixed' (Wendell, 1996; Oliver, 2009). The social model, on the other hand, separates having an impairment from being disabled, with people with an impairment being disabled by society (Shakespeare, 2018). Many different specific definitions of impairment and disability exist, and these definitions are often criticised, although they are typically at least partly based on this social model. Although the individual/medical and social models are not the only approaches to disability, there is no clear consensus on which approaches to use (see e.g. Oliver, 2009) and these models provide a useful start for our discussion.

Here we use Thomas's (1999) definitions. She defines disability using a 'social relational approach', stating that 'disability expresses an unequal social relationship between those who are impaired and those who are non-impaired, or 'normal', in society' (Thomas, 1999: 40). On the basis of this distinction, disability is considered 'like patriarchy ... a form of social oppression' (Thomas, 1999: 40; see also Union of the Physically Impaired Against Segregation, 1976; Oliver, 2009). From this distinction between impairment and disability we can also characterise disablism. Disablism can be defined as the manifestation of disability 'through exclusionary and oppressive practices .... at the interpersonal, organizational, cultural and sociostructural levels in particular societal contexts' (Thomas, 1999: 40). Disability and disablism in this perspective are not characteristics of the individual, but manifest through social relations.

This does not deny that impairments may have effects. Thomas (1999) carefully discusses what she understands as 'impairment'; this is, according to her, not unproblematically referring to 'the body', but also not 'just' a social construct that bears no relationship to 'the body'. The social model of disability is sometimes criticised for not taking the body into account enough (see e.g. Gilleard and Higgs, 2014; for a counter-view, see Oliver, 2009). Thomas (1999: 124) defines 'impairment' as 'those body-related variations which in Western culture have become markers of socially, or more precisely medically, defined "significant deviations from 
the normal type" or "abnormalities". These can include various things, including physical impairments, sensory impairments, learning difficulties, mental health conditions and chronic illnesses (Shakespeare, 2018).

Impairment effects are in turn defined as

the restrictions of activity which are associated with being impaired but which are not disabilities in the social relational sense. Impairment effects may become the medium of disability in particular social contexts. Care must always be taken, of course, not to mistake impairment effects for what are, in fact, disabilities. (Thomas, 1999: 43)

It is also important to remember that an impairment effect can vary in its degree and should be seen on a continuum, although often it is thought of from one extreme or the other, i.e. being very affected or not at all (cf. Shakespeare, 2018).

As can be seen in the definitions of impairment and disablism, what is 'disabled' cannot be separated from what is 'abled'; what is 'normal' cannot be separated from what is considered 'abnormal'. In line with this, Goodley (2014) suggested a split term dis/ability to explore the 'co-construction and reliance upon one another'. Next to disablism, ableism is also an often-used term, sometimes used interchangeably, sometimes argued to be distinct from one another (see e.g. Campbell, 2009). In this paper, we use ableism to refer to a

network of beliefs, processes and practices that produces a particular kind of self and body (the corporeal standard) that is projected as the perfect, species-typical and therefore essential and fully human. Disability then is cast as a diminished state of being human. (Campbell, 2001: 44)

\section{Defining ageism}

The concept of 'ageism' has been attributed to Butler (1969). He defined ageism as 'prejudice by one age group toward other age groups' (Butler, 1969: 243). In his paper, he already combines ageism with disability when talking about ageism towards older people: 'Age-ism reflects a deep seated uneasiness on the part of the young and middle-aged - a personal revulsion to and distaste for growing old, disease, disability; and fear of powerlessness, "uselessness," and death' (Butler, 1969: 243). Since his definition of ageism, various others have been proposed. It is beyond the scope of this paper to discuss all definitions. To give just one, relatively recent, example: Azulai (2014: 5) defines ageism as 'a multidimensional concept, which incorporates ageist stereotypes (both positive and negative beliefs), prejudicial and stigmatizing attitudes, and age-based discrimination'. Ageist stereotypes of older workers include that they are more reliable and experienced than younger workers, but simultaneously are less competent, with limited physical or mental capacity, decreased willingness to participate in training, technological incompetence and less flexibility (Harris et al., 2018). A problem is that ageism can be too broadly defined, making it unclear what ageism precisely is, how it works and how it should be addressed. Hence, we propose to redefine ageism, making the definition narrower and distinguishing it from ableism. 
Ageism could be defined using the 'social relational approach', following Thomas's (1999) definition of disablism. Ageism would then be an unequal social relationship between various age groups in society and could be, like disability and patriarchy, a form of social oppression. This unequal social relationship would manifest 'through exclusionary and oppressive practices ... at the interpersonal, organizational, cultural and socio-structural levels in particular societal contexts' (Thomas, 1999: 40). Ageism, like disablism, would not be a characteristic of the individual, but exist through social relations. In our definition, ageism would be differential treatment based on age, not based on impairments. Differential treatment based on (real or expected) impairments would be ableism. For example, there are some indications that bias in providing psychological services may be related to stereotypes of individuals in poorer physical health, rather than differential treatment based on age per se (Nelson, 2005). Hence, some differential treatment may be based on impairments that older people may be more likely to have, rather than on age. In our definition, this would fall under ableism rather than ageism.

In line with Thomas's (1999) work on disablism, we would argue for separating ageism from age and ageing effects. People do change when they get older, e.g. getting facial wrinkles, experiencing some degree of hearing loss, etc.; there is an age progression in how bodies and minds change as individuals age (though not particular to specific ages and with variation between individuals). These age-related changes (i.e. age effects) that people do experience and talk about, should not be denied. They should be separated from impairments, however, as they may not be at the level of medically decided 'significant deviations from the normal type' a concept that is problematic in itself. A person may start at a high level of hearing and become less good at hearing, but still be among people who are hearing very well. This person may talk about having diminished hearing, but others may not notice it and medically the person would be considered as hearing well (within 'normal' ranges).

Furthermore, care must be taken with regard to what is considered an 'age effect'. For example, correlations with age should not be considered an 'age effect'. Overall (2006) has already mentioned the imperfect correlation between old age and arthritis, arguing it is not an 'age effect' as people of various ages have it and many older people will never get it. Also, some things may be thought of as 'age effects' but are in fact not, as they are consequences of differential treatment of people of various ages. For example, Nelson (2016) points to research showing how memory is affected by old-age stereotypes. Becca Levy and colleagues have done much work on how age stereotypes affect health outcomes, leading to the Stereotype Embodiment Theory (Levy, 2009) (for a recent systematic review of research based on this theory, see Chang et al., 2020).

In practice, it may be difficult to always distinguish age effects from impairment effects and ageism from ableism. However, we think this would be a worthwhile effort as solutions or remedies may differ depending on whether we are talking about age versus impairment effects and ageism versus ableism. For example, if an older worker was not offered a career development opportunity because it was assumed that she might be nearing retirement and hence would not be interested in the opportunity, this would be ageism and not ableism. Strategies to 
circumvent these situations may, for example, be sought in age discrimination legislation and by educating employers. If, however, the older worker was not offered this career development opportunity because it was assumed that she will not be hearing well enough, especially if the older worker herself also says she is not hearing as well as she used to (as an age effect), this would be ableism rather than ageism. Solutions may be sought in how to make the training more inclusive for people with various hearing abilities regardless of the age of the person in training, rather than in age discrimination legislation, and educating employers in seeing hearing ability as a continuum rather than 'people who hear well' versus 'people who cannot hear (well)'.

\section{Previous research on ageism versus ableism}

The link between age and dis/ability has often been made. For example, it is argued that because ageing is associated with a decline in mental and physical abilities, connotations with being 'old' tend to be negative (Ayalon and Tesch-Römer, 2018; Harris et al., 2018). Individuals therefore actively distance themselves from being 'old' and do not consider themselves 'old' yet as they do not 'feel' old (Minichiello et al., 2000). Gendron et al. (2018: 620) refer to the word 'still', when people describe themselves as 'I still feel 60 '. As a result, much of what individuals describe as being ageism may in fact be ableism and a fear of disability.

Trying to disentangle ageism from ableism may become increasingly difficult. The question has been posed whether (or mentioned as a fact that) ageing itself is an 'illness' that needs to be 'cured'. For example, Calasanti and Slevin (2001: 16) write, in the context of the United States of America, about the damaging tendency for growing old to be seen as something to be 'treated and cured' (for some of the discussion around this, see e.g. Gems, 2014; Kritchevsky, 2019). In this narrative, ageing itself appears to become an impairment. As Thomas (1999: 133) states 'what is and what counts as impairment is always socially located, situated in time and place'. This would, however, locate ageism even more in the field of ableism.

Previous research has mentioned possible intersections among ageism and ableism (see e.g. Gibbons, 2016; Bartlett and Kafer, 2020), especially in response to the 'successful ageing' narrative that is considered 'inherently ageist and ableist' (Westwood and Carey, 2019: 226). Narratives surrounding successful ageing are said to be rooted in the medical model of disability (Berridge and Martinson, 2018). Gibbons (2016) warns that there is a danger in redefining ageism as ableism as this would prevent us from assessing intersections between the two and ignores ageism experienced by non-disabled older people. We instead consider only part of what has been referred to as ageism to be ableism and argue in favour of analytically distinguishing these concepts better. Although other researchers have talked about possible overlaps between disability and ageing studies, there is still much work to be done to bring this into practice (see e.g. Bartlett and Kafer, 2020). Strategies to decrease ageism may depend on whether it is about age or (expected) dis/ability (as already explained above) and it may be worthwhile disentangling them more. It is then also important to assess its intersections, as ableism may depend on age and ageism may depend on dis/ability. 


\section{Ageism versus ableism among older workers}

Focusing the discussion for now on the labour market, disability literature has long studied labour market inequality and points to a disability gap in employment. Existing research demonstrates that people with a disability experience difficulty entering the labour market, as well as exclusion and marginalisation once employed, and recently ableism has been used as a theoretical lens to look at this (see Jammaers et al., 2019). We explore the degree to which we can integrate knowledge gathered from critical (feminist) disability studies into our understanding of ageism at work. Although a full discussion is beyond the scope of this paper, we try to take some first steps in bringing the fields closer together. Finally, we argue that not all ageism is likely to be ableism, suggesting that ageism remains a useful concept.

\section{Disembodiment of jobs}

Feminist work has pointed to the disembodiment of jobs as an important reason for gender differences in work:

In organizational logic, both jobs and hierarchies are abstract categories that have no occupants, no human bodies, no gender ... In organizational logic, filling the abstract job is a disembodied worker who exists only for the work. Such a hypothetical worker cannot have other imperatives of existence that impinge upon the job. (Acker, 1990: 149)

Foster and Wass have applied the organisational logic discussed in Acker (1990) to people with an impairment:

If impairment does limit ability, flexibility or efficiency, we further speculate that the gap between the ideal person outlined in a standard job specification and the person with an impairment may in some sense be perceived as being real, thereby 'legitimising' discrimination against a disabled employee. (Foster and Wass, 2013: 709-710)

The same logic is likely to be applied to older workers. With older workers assumed to have limited or progressively limiting physical or mental capacity, they would fit the abstract disembodied job less well than younger workers. However, if there was no ableism, it is unlikely that older workers would still be treated differently based on this stereotype. They may still be regarded differently based on having (assumed) more experience in the job and (assumed) less willingness to change. Hence, the organisational logic may still lead to ageism, but to a (much) lower degree compared to if there were no ableism.

Impairments may limit ability to do certain jobs in ways less true for other sources of discrimination, as Foster and Wass comment:

In some employment contexts it may be the case that a disabled person cannot genuinely perform a task: a scenario less likely to occur as a consequence of a person's class, sexuality, race or (in most but not all circumstances, e.g. physically 
demanding work) gender. However, as Acker's example of gender and job evaluation demonstrates, there are ways of looking at a job and acknowledging that there is ideological baggage that accompanies it, for example, that it is designed around a male norm. (Foster and Wass, 2013: 710)

Hence, the abstract job asks for an ideal worker to fill the job. This ideal worker assumption that lies behind jobs may be particularly important in the current labour market. In the literature on ageing, modernisation has been identified as a source of the declining status of older people (De Tavernier et al., 2019). As Ayalon and Tesch-Römer (2018: 7) argue, with technology and medicine keeping more older people alive, older age has become 'a common occurrence generally associated with frailty, morbidity, and disability', increasing the possible link between ageism and ableism. At the same time, the knowledge of older people which may previously have been valued (sometimes referred to as 'sageism' - see e.g. Minichiello et al., 2000) is less necessarily due to technological advances (Ayalon and Tesch-Römer, 2018). Modernisation also describes how the structure of the labour market has changed to more competitiveness and emphasis on productivity, which is stereotypically bad for various sub-groups of workers, including older workers (Stypińska and Nikander, 2018). Work has intensified and many jobs became more complex throughout the 1980s and 1990s, and workers report having to work harder and faster while the time for rest is reduced (Foster and Wass, 2013). Goodley (2014: 29) writes in this respect about 'compulsory neoliberal able-bodiedness' and that the reference to which everyone is compared is 'young and strong'. Changes to the labour market may therefore have added criteria to what the ideal worker looks like. However, it is unlikely in many cases that it is about age per se, but more about perceived ability, and hence more about ableism than ageism.

Strategies to diminish ageism are then unlikely to be effective when focusing on age per se. Changing the stereotypes of older workers to exclude older workers with health issues is likely to increase ableism towards individuals of all ages with an impairment, including older workers with an impairment. However, changing the organisational logic to bring the body back in and have the job fit the person, rather than the person fit the job, makes it unimportant if the older worker does or does not have an impairment or needs adjustments for other reasons. Rather than assuming that there is an abstract job that can easily be replaced by hiring someone else to do exactly that job, it should be acknowledged that each person is different, with their own skills and challenges, and there is no 'typical or ideal employee' ( $c f$. Foster and Wass, 2013). By diminishing ableism in the way jobs are structured, ageism is also likely to diminish.

\section{Pretending to be young and healthy - the problem of distinguishing third and fourth age}

Higgs and Gilleard (2020) recently also argued that there is some ambiguity around what is meant by 'ageism' and suggested instead using the 'social imaginary of the fourth age' by distinguishing the 'third age' (an 'aspirational later life') from the 'fourth age' (a 'feared later life') that is characterised by frailty and a care-need 
(though they do make an argument for a more limited use of 'ageism'). This distinction between the third and fourth ages is based on Laslett, who described the ages as:

first comes an era of dependence, socialization, immaturity and education; second an era of independence, maturity and responsibility, of earning and of saving; third an era of personal fulfilment; and fourth an era of final dependence, decrepitude and death. (Laslett, 1991: 4)

Though referring to ages, it is claimed that these stages should not be considered age-specific nor necessarily following each other, as the third age may be lived simultaneously as the first or second age (Laslett, 1991). When theorising about the fourth age, Gilleard and Higgs (2010: 126) also argue that 'the fourth age [should] not [be considered] as a particular age cohort or distinct phase of life'. This suggestion separates older people with (severe) health problems from older people without, and this seems to be what distinguishes the third from the fourth age.

A strategy to deal with the ideal worker (or if we extend this to outside paid work, the ideal citizen) narrative is trying to 'pass as normal'. The distinction between the third and fourth ages, as proposed by Gilleard and Higgs, is also based on the degree someone is still able to pass as 'young and healthy', as explained below.

Research on ableism discusses how individuals try to 'pass for normal' to avoid negative consequences of having a disability (see e.g. Barnes and Mercer, 2010: 53). With regard to ageism, the 'normal' that individuals try to 'pass as' is being 'young' or at least 'not old'. Several studies have found that individuals actively distance themselves from the label being 'old' (see e.g. Gendron et al., 2018), and this is a finding that has been reoccurring for over 40 years ( $c f$. Calasanti and Slevin, 2001). However, when they distinguish themselves from being 'old', older workers do this by distancing themselves from being frail. Because they still feel healthy, they are not yet 'old'. This can also be reversed in daily conversation; Gendron et al. (2018: 620) give the example: 'people saying, "Today I feel 104" due to fatigue, illness, pain or the like'. It has been claimed that '[e]fforts to counter ageism by emphasizing the positive features of old age simply transfer old ageist stereotypes to those who have disabilities' (Holstein, 1994: 21). Loretto (2010: 290) argues that employers only want to employ older workers if they remain fit and healthy.

For both fields, there are indications that the counter-narrative may be problematic. For example, when talking about 'active ageing', the comparison is the 'younger worker' and how good the older worker or retiree is at 'keeping up' (cf. Calasanti, 2005; Lotherington et al., 2017). Focusing on productivity and being active means that individuals who are unable or unwilling to adhere to this paradigm are a 'problem' (Calasanti and Slevin, 2001: 183). The distinction between the third and fourth ages

helps distance longer lives and later lifestyles from the abjection of old age, and at the same time it intensifies the horror with which 'real' old age is viewed, a horror at the otherness of the orphaned and decaying body. (Gilleard and Higgs, 2011: 138) 
It also helps create a 'normative life-course' that 'presumes independence, productivity, and reproduction as key markers of value' (cf. Bartlett and Kafer, 2020: 255). It has been argued that a risk of positive ageing narratives is that they obscure the needs that older adults do have (Berridge and Martinson, 2018).

Gilleard and Higgs see being able to 'overcome' a disability as a positive way to avoid images of being older or disabled:

People who cannot walk well or who cannot walk at all can still perform acts that garner social esteem - in part through the very determination with which they conduct themselves. People in wheelchairs climbing mountains, people painting with no hands, using their teeth or their toes instead to hold the brushes, people lecturing students using computer mediated speech - all these acts transgress what otherwise might be seen as the embodied abjection of agedness or disablement. (Gilleard and Higgs, 2011: 139)

Wendell (1996) calls these 'disabled heroes' which is criticised as giving nondisabled people the unrealistic idea that everyone can 'overcome' their disability (also see Barnes and Mercer, 2010). Once a person cannot effortlessly pass as a social actor, failing at certain activities (such as walking without falling), there is a lack of 'self control' and 'self direction' that Gilleard and Higgs (2011) refer to as the core of abjection. Hence, for both ageism and ableism, a strategy has been to try to 'pass' as (still) young and healthy rather than challenge the assumption that everyone has to be productive and active, and what it means to be productive and active for people who are not middle-aged and healthy (and male). The distinction between the third and fourth ages does not overcome this problem and may in fact intensify it and increase ableism of all ages.

\section{If we get rid of ableism, would there still be ageism?}

As mentioned earlier, not all ageism is likely to be ableism. Above, we explained that the ideal worker paradigm may still affect older workers to some degree if there was no ableism. Here we consider further theoretical perspectives that would suggest that at least some ageism will remain. A first explanation is the role congruity theory: originally this was used to theorise about gender differences in the labour market and, more specifically, the glass ceiling. The basic idea is that the female gender role is considered to be incompatible with leadership roles. A more general version of this theory states that certain characteristics of a social group are seen as incompatible with certain requirements of social roles, which means that the stereotyped person is perceived as a less good candidate for a potential or actual role (for more detail, see Eagly and Karau, 2002). This has also been applied to research on ageism and 'the silver ceiling', with the central premise that when there appears to be a 'lack of fit' between being older and a certain role then the older person is perceived less positively than a younger person (Diekman and Hirnisey, 2007). To the degree that older workers are perceived as old-fashioned, they may be identified as being incompatible with an organisation that portrays itself as 'young and hip'. Diekman and Hirnisey (2007), in three experiments performed on students, found evidence for the role congruity theory. More specifically, 
older candidates were perceived less favourably than younger candidates for more dynamic settings.

A second example is the terror management theory, which assumes that individuals need positive self-esteem to combat vulnerability and mortality terror (Greenberg et al., 1986). In the ageism literature this has been used to see older people as a reminder of one's own mortality and vulnerability, and consequently a threat to one's self-esteem (e.g. Ayalon and Tesch-Römer, 2018). Even without ableism, ageism may thus continue as older people serve as a reminder of one's own mortality. For older workers this may be less important as many will be relatively healthy and have many years to live, but also in the workplace this fear could lead to unease when working with older colleagues (see e.g. Fasbender, 2016).

A final example is the intergenerational conflict theory which would predict that younger people are expecting a succession of resources and that older people will take fewer resources (Ayalon and Tesch-Römer, 2018). Younger workers may expect older workers 'to make space' for them, allowing them to advance their career. This is likely to remain if there was no ableism. All three explanations would work using a 'social relational approach' to ageism.

\section{Concluding remarks}

The main argument of this article is the need to redefine ageism and take ableism into account more. It is increasingly acknowledged that 'ageism' is a concept that is not (yet) well understood. We agree with Higgs and Gilleard (2020: 1618) that it is not useful if ageism is used as a catch-all concept. However, there is a danger in the alternative they suggest: the distinction between a third and a fourth age. The solution we propose is to distinguish more clearly ageism from ableism. For both, we propose to use a social-relational definition, and to separate it from age and impairment effects. This redefinition may provide guidelines to researchers on how to study ageism, without the problem that ageism means too many things and becomes useless.

Furthermore, if elements of ageism would not exist if there were no ableism, it is unlikely to be resolved by finding solutions for ageism, but it should be solved by strategies to diminish ableism. We expect that (a) ageism would also reduce if ableism is successfully diminished and (b) that these solutions are more likely to succeed if ableism in general is fought than if only ageism is addressed. One example of this may be addressing the organisational logic and bringing the body back in the job, recognising that in reality there are no abstract disembodied jobs. We do expect that ageism would remain to some degree if there were no ableism. However, by distinguishing when it is about ableism and when about ageism, alternative strategies can be developed for the different struggles older people in general, and older workers specifically, experience.

As a final note, ageism may depend on ableism and vice versa, and strategies may sometimes differ depending on the intersections of these two. Our suggestion for more clearly separating the concepts should therefore not be interpreted as a call to no longer look at intersections. Moreover, it will also be important to take into account further intersections, e.g. with sexism and racism. More research on these intersections is necessary. 
Acknowledgements. The authors would like to thank Ben Baumberg Geiger and two anonymous reviewers for their helpful feedback on earlier versions.

Financial support. This work was supported by the Economic and Social Research Council (ESRC) in the UK (grant number ES/S00551X/1).

\section{References}

Acker J (1990) Hierarchies, jobs, bodies: a theory of gendered organizations. Gender and Society 4, 139-158.

Ayalon L and Tesch-Römer C (2018) Introduction to the section: Ageism - concept and origins. In Ayalon L and Tesch-Römer C (eds), Contemporary Perspectives on Ageism (International Perspectives on Aging 19). Berlin: Springer Open, pp. 1-10.

Azulai A (2014) Ageism and future cohorts of elderly: implications for social work. Journal of Social Work Values and Ethics 11, 2-12.

Barnes C and Mercer G (2010) Exploring Disability, 2nd Edn. Cambridge: Polity Press.

Bartlett R and Kafer A (2020) Thinking into aging-disability nexuses: A dialogue between two scholars. In Aubrecht K, Kelly C and Rice C (eds). The Aging-Disability Nexus. Vancouver, Canada: UBC Press, pp. 251-267.

Berridge CW and Martinson M (2018) Valuing old age without leveraging ableism. Generations 41, 83-91.

Butler RN (1969) Age-ism: another form of bigotry. The Gerontologist 9, 243-246.

Calasanti T (2005) Ageism, gravity, and gender: experiences of aging bodies. Generations 29, 8-12.

Calasanti TM and Slevin KL (2001) Gender, Social Inequalities, and Aging (The Gender Lens Series). Walnut Creek, CA: AltaMira Press.

Campbell FAK (2001) Inciting legal fictions: disability's date with ontology and the ableist body of the law. Griffith Law Review 10, 42-62.

Campbell FK (2009) Contours of Ableism: The Production of Disability and Abledness. Basingstoke, UK: Palgrave Macmillan.

Chang E-S, Kannoth S, Levy S, Want S-Y, Lee JE and Levy BR (2020) Global reach of ageism on older persons' health: a systematic review. PLOS ONE 15, e0220857.

De Tavernier W, Naegele L and Hess M (2019) A critical perspective on ageism and modernization theory. Social Inclusion 7, 54-57.

Diekman AB and Hirnisey L (2007) The effect of context on the silver ceiling: a role congruity perspective on prejudiced responses. Personality and Social Psychology Bulletin 33, 1353-1366.

Eagly AH and Karau SJ (2002) Role congruity theory of prejudice toward female leaders. Psychological Review 190, 573-598.

Fasbender U (2016) Stereotype, prejudice and discrimination toward older workers: a wind of change? In Burke R, Cooper C and Antoniou A (eds), The Aging Workforce: Individual, Organizational and Societal Challenges. London: Emerald Publishing, pp. 159-184.

Foster D and Wass V (2013) Disability in the labour market: an exploration of concepts of the ideal worker and organisational fit that disadvantage employees with impairments. Sociology 47, 705-721.

Gems D (2014) What is an anti-aging treatment? Experimental Gerontology 58, 14-18.

Gendron TL, Inker J and Welleford A (2018) 'How old do you feel?' The difficulties and ethics of operationalizing subjective age. The Gerontologist 58, 618-624.

Gibbons HM (2016) Compulsory youthfulness: intersections of ableism and ageism in 'successful aging' discourses. Review of Disability Studies: An International Journal 12, 1-19.

Gilleard C and Higgs P (2010) Aging without agency: theorizing the fourth age. Aging \& Mental Health 14, 121-128.

Gilleard C and Higgs P (2011) Ageing abjection and embodiment in the fourth age. Journal of Aging Studies 25, 135-142.

Gilleard C and Higgs P (2014) Ageing, Corporeality and Embodiment. London: Anthem Press.

Goodley D (2014) Dis/Ability Studies: Theorising Disablism and Ableism. London: Routledge.

Greenberg J, Pyszcynski T and Solomon S (1986) The causes and consequences of a need for self-esteem: a terror management theory. In Baumeister R (ed.), Public Self and Private Self. New York, NY: Springer, pp. 189-212. 
Harris K, Krygsman S, Waschenko J and Rudman DL (2018) Ageism and the older worker: a scoping review. The Gerontologist 58, e1-e14.

Higgs P and Gilleard C (2020) The ideology of ageism versus the social imaginary of the fourth age: two differing approaches to the negative contexts of old age. Ageing \& Society 40, 1617-1630.

Holstein M (1994) Changing concepts: visionary or short-sighted. Ageing International 11, 20-22.

Jammaers E, Zanoni P and Williams J (2019) Not all fish are equal: a Bourdieuan analysis of ableism in a financial services company. International Journal of Human Resource Management. Available online doi:10.1080/09585192.2019.1588348.

Kritchevsky SB (2019) Is old age or aging a disease, in a literal or a metaphorical sense? Public Policy \& Aging Report 29, 123-125.

Laslett P (1991) A Fresh Map of Life: The Emergence of the Third Age. Cambridge, MA: Harvard University Press.

Lee J, Wilson JM and Shook NJ (2019) What is ageism? A review and analytical critique of current measures of ageism. Austin, Texas, Poster presented at GSA November 2019.

Levy B (2009) Stereotype embodiment: a psychosocial approach to aging. Current Directions in Psychological Science 18, 332-336.

Loretto W (2010) Work and retirement in an ageing world: the case of older workers in the UK. Twenty-first Century Society: Journal of the Academy of Social Sciences 5, 279-294.

Lotherington AT, Obstfelder A and Halford S (2017) No place for old women: a critical inquiry into age in later working life. Ageing \& Society 37, 1156-1178.

Minichiello V, Browne J and Kendig H (2000) Perceptions and consequences of ageism: views of older people. Ageing \& Society 20, 253-278.

Nelson TD (2005) Ageism: prejudice against our feared future self. Journal of Social Issues 61, 207-221.

Nelson TD (2016) Promoting healthy aging by confronting ageism. American Psychologist 71, 276-282.

Oliver M (2009) Understanding Disability: From Theory to Practice (2nd Edn). Basingstoke, UK: Palgrave Macmillan.

Overall C (2006) Old age and ageism, impairment and ableism: exploring the conceptual and material connections. NWSA Journal 18, 126-137.

Shakespeare T (2018) Disability: The Basics. New York, NY: Routledge.

Stypińska J and Nikander P (2018) Ageism and age discrimination in the labour market: a macrostructural perspective. In Ayalon L and Tesch-Römer C (eds), Contemporary Perspectives on Ageism (International Perspectives on Aging 19). Berlin: Springer Open, pp. 11-31.

Thomas C (1999) Female Forms: Experiencing and Understanding Disability. Buckingham, UK: Open University Press.

Union of the Physically Impaired Against Segregation (1976) Fundamental Principles of Disability. London: Union of the Physically Impaired Against Segregation.

Wendell S (1996) The Rejected Body: Feminist Philosophical Reflections on Disability. New York, NY: Routledge.

Westwood S and Carey N (2019) Ageing with physical disabilities and/or long-term health conditions. In Westwood S (ed). Ageing Diversity and Equality: Social Justice Perspectives. London: Routledge, pp. 225244 .

Cite this article: van der Horst M, Vickerstaff S (2022). Is part of ageism actually ableism? Ageing \& Society 42, 1979-1990. https://doi.org/10.1017/S0144686X20001890 